\title{
Gaussian Mixture Models for Robust Unsupervised Scanning-Electron Microscopy Image Segmentation of North Sea Chalk
}

Sören Dramsch, Jesper; Amour, Frédéric; Lüthje, Mikael

Published in:

Proceedings of the First EAGE/PESGB Workshop on Machine Learning (London2018)

Link to article, DOI:

$10.3997 / 2214-4609.201803014$

Publication date:

2018

Document Version

Publisher's PDF, also known as Version of record

Link back to DTU Orbit

Citation (APA):

Sören Dramsch, J., Amour, F., \& Lüthje, M. (2018). Gaussian Mixture Models for Robust Unsupervised Scanning-Electron Microscopy Image Segmentation of North Sea Chalk. In Proceedings of the First EAGE/PESGB Workshop on Machine Learning (London2018) (pp. 28-30). European Association of Geoscientists and Engineers. https://doi.org/10.3997/2214-4609.201803014

\section{General rights}

Copyright and moral rights for the publications made accessible in the public portal are retained by the authors and/or other copyright owners and it is a condition of accessing publications that users recognise and abide by the legal requirements associated with these rights.

- Users may download and print one copy of any publication from the public portal for the purpose of private study or research.

- You may not further distribute the material or use it for any profit-making activity or commercial gain

- You may freely distribute the URL identifying the publication in the public portal 


\section{Introduction}

In the oil and gas industry, assessment and prediction of the hydrocarbon reserves and flow properties throughout a chalk reservoir lifetime relies, among others, on conventional and special core analysis (CCAL and SCAL) and computed tomography (CT) imaging in order to characterise the petrophysical properties and 3-D pore network geometry of chalk.

The latter laboratory experiments are technically challenging, costly, and time-consuming and require a large amount of core material. Various image analysis techniques, studying the 2-D distribution of grains, pores, and pore throats on thin-sections, have been extensively tested over more than 50yrs for workflow optimization.

Nevertheless, such techniques have not yet been integrated by reservoir engineers and geoscientists as a routine task during reservoir characterization, especially, due to a limited number of samples tested or a spatially-restricted study area that do not allow the results to be statistically representative of the chalk heterogeneity across a reservoir and between oil and gas fields.

Back-scattered electron microscopy (BSEM) analysis historically has been very manual work. Separating grains from the background, measuring perimeter and area of the grains. Recently, publications showed automatic segmentation of BSEM images using computational methods. The present study represents a robust method in the application of machine learning on thin-section images collected by BSEM. This cheap and relatively rapid technique allows to quickly analyse a large number of pictures that do not need to be manually labeled.

\section{SEM Analysis as Image Segmentation}

Scanning Electron Microscopy (SEM) is an imaging method that allows the visualisation of the grains and pores of chalk deposits (Figure 1). Grayscale images of the rock fabric can be collected at various scales of observation, from the micro-scale, typically single pore and grain, to few tens of microns where the network of pores can be studied, to the millimetres-scale. This provides a complete insight of the heterogeneity of each sample. Nanotube SEM and many applications separate very well the grains from the background in the SEM images. Therefore, these images can be segmented by histogram methods. Carbonates and specifically chalk vary on grayscale, and grains are not illuminated homogeneously. However, image segmentation has made many improvements in recent years, which extends the toolkit beyond histogram segmentation.
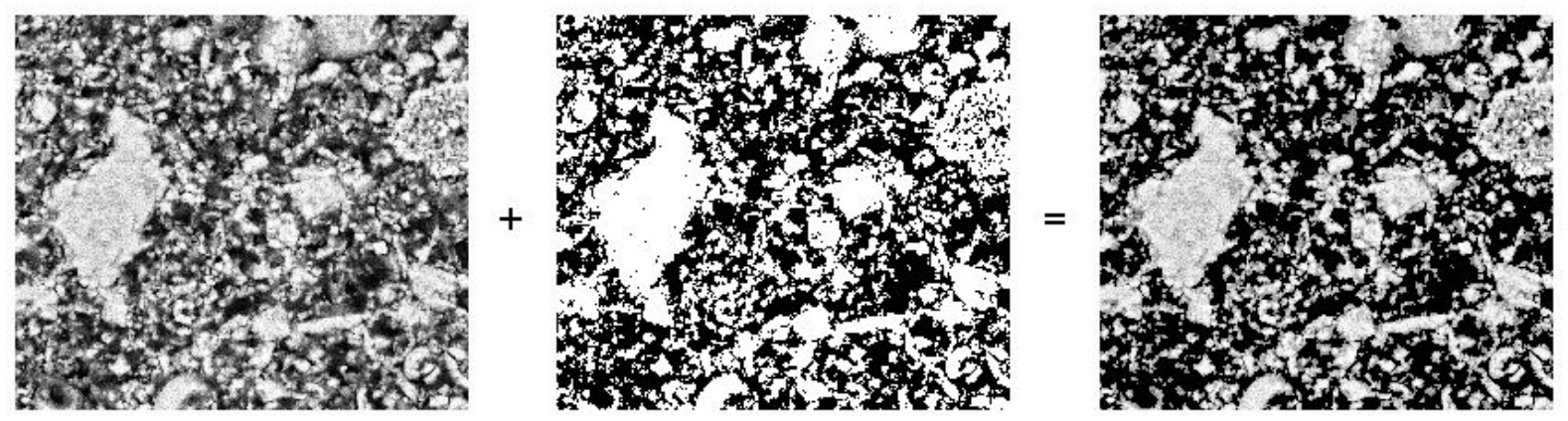

Figure 1: Original SEM image, binary mask obtained by GMM, and resulting grain image.

Modern Neural Networks (NN) can segment images exceptionally well (Ronneberger et al. 2015). Modarres et al. (2017) investigated the application of NNs to SEM images. However, as with most applications in Geoscience and supervised learning, we would have to label a significant amount of images by hand to assure quality or automatically with subpar methods to train the network adequately. This defeats the point for this application, therefore, this study investigates unsupervised methods, which will be assessed in order to select the one that performs the best across all scales of 


\section{PES،GB}

observation. Several BSEM images of the rock fabric at the same scale are also collected to validate the results.

Gaussian Mixture Model (GMM) learns a number of joint distributions approximated by Gaussians in the search space (Lindsay, 1995). The number of Gaussians has to be specified, similar to many clustering methods, like k-means. In this application, we aim at segmenting the background from the chalk, which lends itself to specify two Gaussian distributions as learning parameter to obtain a binary mask, presented in Figure 1.

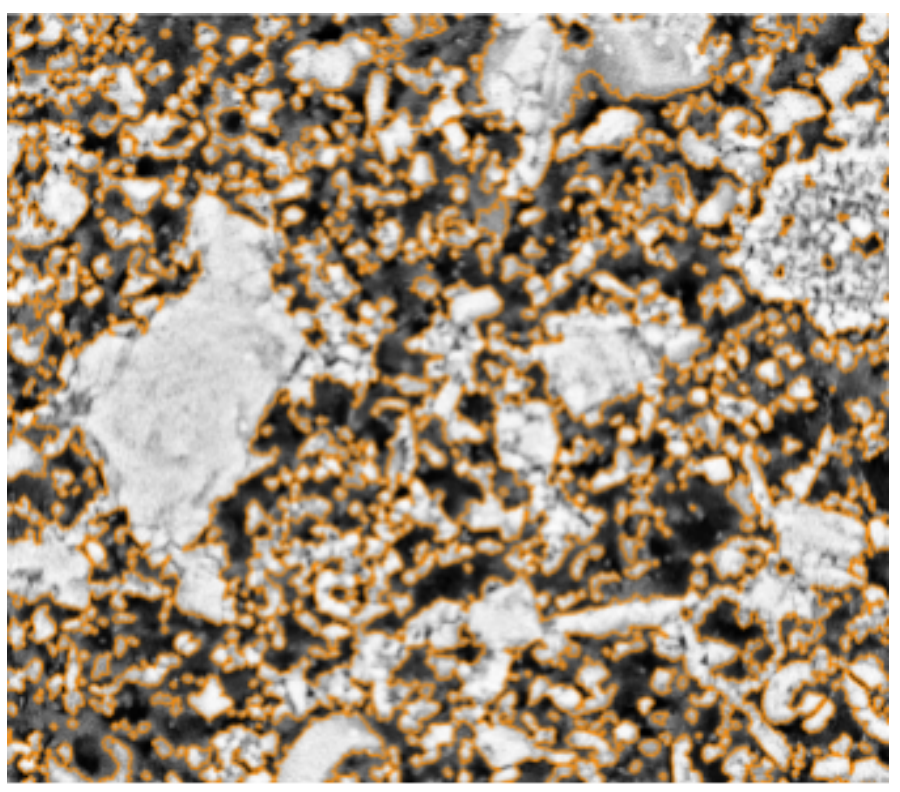

Figure 2: Filtered segmentation of BSEM

\section{Morphological Filtering}

We apply morphological filtering to clean up the segmentation (Serra and Vincent 1992). Due to the noisy images of BSEM, the edges of grains appear fuzzy. For the automatic analysis of the perimeter for instance, seen in Figure 2.

Subsequently, we can programmatically analyse the result using scikit-learn and scikit-image (Pedregosa 2011). This provides area, perimeter and rotation of grains in the image among other geometrical factors of the grains. These can be very valuable in digital rock physics and pore analysis.

\section{Conclusions}

We present an effective segmentation method for BSEM image data. Gaussian Mixture Models learn a good representation of the grayscale data and morphological filtering further improves the results.

\section{Acknowledgements}

The research leading to these results has received funding from the Danish Hydrocarbon Research and Technology Centre under the Advanced Water Flooding program.

\section{References}

Lindsay, B. G. (1995, January). Mixture models: theory, geometry and applications. In NSF-CBMS regional conference series in probability and statistics (pp. i-163). Institute of Mathematical Statistics and the American Statistical Association.

Modarres, M. H., Aversa, R., Cozzini, S., Ciancio, R., Leto, A., \& Brandino, G. P. (2017). Neural Network for Nanoscience Scanning Electron Microscope Image Recognition. Scientific reports, 7(1), 13282.

Pedregosa, F., Varoquaux, G., Gramfort, A., Michel, V., Thirion, B., Grisel, O., ... \& Vanderplas, J. (2011). Scikit-learn: Machine learning in Python. Journal of machine learning research, 12(Oct), 2825-2830.

Ronneberger, O., Fischer, P., \& Brox, T. (2015, October). U-net: Convolutional networks for biomedical image segmentation. In International Conference on Medical image computing and computer-assisted intervention (pp. 234-241). Springer, Cham.

Serra, J., \& Vincent, L. (1992). An overview of morphological filtering. Circuits, Systems and Signal Processing, 11(1), 47-108. 